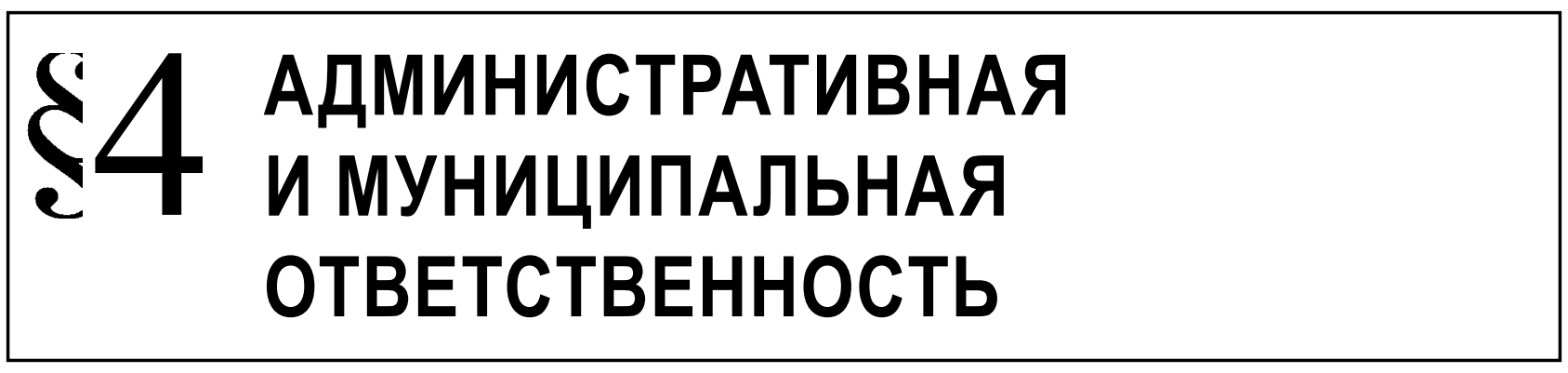

Громова Г.А.

\title{
НЕКОТОРЫЕ ПРОБЛЕМЫ ПРАВОВОГО РЕГУЛИРОВАНИЯ ОБРАЩЕНИЯ С МЕДИЦИНСКИМИ ОТХОДАМИ И ПРИВЛЕЧЕНИЯ К АДМИНИСТРАТИВНОЙ ОТВЕТСТВЕННОСТИ ЗА НАРУШЕНИЯ ПРИ ОБРАЩЕНИИ С МЕДИЦИНСКИМИ ОТХОДАМИ
}

Аннотация: Медицинские отходы, образуемые в процессе медицинской и фармацевтической деятельности, представляют собой потенциальную опасность как для лиц, задействованных в обращении с медицинскими отходами, так и для окружающей среды и для жизни и здоровья неопределенного круга лиц. Поэтому вопросы обращения и уничтожения отходов, образуемых лечебно-профилактическими учреждениями, особо актуальны. В связи с изложенным, в статье излагаются теоретические и практические проблемы привлечения к ответственности лиц, нарушающих порядок обращения медицинских отходов. Приводится в сравнение классификация отходов в зависимости от степени негативного воздействия на окружающую среду, изложенная в Федеральном законе от 24 июня 1998 г. N 89-Ф3 "Об отходах производства и потребления", а также классификация медицинских отходов, приведенная федеральным классификационным каталогом отходов, утвержденным приказом Министерства природных ресурсов Российской Федерации от 02.12.2002 N 786, для медицинских отходов (больниц и лечебно-оздоровительных учреждений). Анализируются вопросы правомерности привлечения к административной ответственности лии, нарушающих порядок обращения с медицинскими отходами, органами, не полномочными вести контроль за соблюдением санитарно-эпидемиологических норм. Применяется сравнительное правоведение помогает выявить различие и общие закономерности развития правовых явлений. Сравнительно правовой метод - необходим при проведении любого научно-правового исследования, поскольку только при помощи такого метода возможно выработать предложения по совершенствованию существующего административного права. Синхронное сравнение (ограничивающееся сравнением в короткие временные циклы). Для сравнения взята российская правовая система (внутреннее сравнение), что позволяет дать общую характеристику определенной правовой системе. Нормативное сравнение -сравниваются сходные правовые нормы, законодательные акты, термины, понятия, классификация. Внутреннее сравнение проведено преимущественно на уровне действующих в одной области правовых норм (микросравнение). Методологическую основу настоящей работы составляет в основном сравнительно-правовой метод исследования. В статье выделяются некоторые проблемы правового регулирования обращения с медицинскими отходами и привлечения к административной ответственности за нарущения при обращении с медицинскими отходами в Российской Федерации, а также выявление недостатков и пробелов в российском законодательстве по исследуемой тематике, разработка рекомендаций по совершенствованию российского законодательства об административно-правовом регулировании обращений медицинских отходов. Вопросы административно-правового регулирования обращения медицинских отходов и привлечения к административной ответственности в данной срере являются достаточно актуальными в связи с внесением в 2008 году изменений в Федеральный закон "Об охране окружающей среды". Выявлена недоработка на законодательном уровне вопросов обращения с медицинскими отходами, что потворствует увеличению числа "уходов" от ответственности виновных организаций, участвующих в обращении медицинских отходов. Отсутствие: 
самого понятия "медицинские отходы"; соответствующего четкого законодательного закрепления вопросов в области лицензирования деятельности в области обращения с медицинскими отходами и паспортизации медицинских отходов; несоответствие классификации медицинских отходов классам опасности, указанным в Федеральном законе "Об отходах производства и потребления" служит причиной недостаточного регулирования и контроля данного вида деятельности и как следствие - неправильного обращения с медицинскими отходами. Что в свою очередь не только повышает возможность непривлечения к ответственности недобросовестных в вопросах обращения с медицинскими отходами учреждений, но и увеличивает риски нанесения ущерба окружающей среде и заражения и травм населения в целом, и работников здравоохранения в частности.

Ключевые слова: отходы, отходы лечебно-профилактических учреждений, медицинские отходы, классификация отходов, лицензирование, паспортизация, ответственность, обращение, сбор отходов, транспортирование медицинских отходов.

$\mathrm{B}$ опросами медицинских отходов были озабочены еще в начале XX века. Так, профессор Р.А.Бабаянц проводил исследования в области определения степени опасности отходов медицинских учреждений. Позже было доказано, что в составе таких отходов находятся возбудители различных заболеваний и токсические вещества: в 1962 году результаты изучения морфологического состава отходов клиники им.Баумана показали обсеменённость болезнетворными микроорганизмами «больничного мусора» значительно выше «городского мусора» ${ }^{1}$. Учитывая такую опасность начиная с 1960 -х годов начинали использоваться мусоросжигательные печи. В настоящее время вопросы сбора, использования, транспортирования, обезвреживания, а также размещения медицинских отходов стоят по-прежнему остро, поскольку они обладают более высоким потенциалом для инфекции и повреждений, чем любой другой тип отходов ${ }^{2}$, а количество таких отходов, а также нарушения в области обращения (то есть деятельности, в процессе которой образуются отходы, а также деятельность по сбору, использованию, обезвреживанию, транспортированию, размещению отходов), с каждым годом возрастают. Представляется, что к вопросам привлечения ЛПУ (лечебно-профилактических учреждений) к административной ответственности необходимо подходить разумно и взвешенно, адекватно оценивая, не допуская недооценки, в то же время не преувеличивая опасность неправильных действий организаций при обращении с медицинскими отходами.

\footnotetext{
1 Опарин П.С. Бактериологическая экспертиза больничных отходов // Эпидемиология и инфекционные болезни. -2002.-№5. - С.35-37

2 Акимкин В.Г. Организационно-эпидемиологические аспекты обращения с отходами лечебно-профилактических учреждений //Эпидемилогия и инфекционные болезни.-2005.-№2. С.4-7
}

В связи с нарушениями в области обращения с медицинскими отходами, проверяющие и судебные органы привлекают лечебно-профилактические учреждения к ответственности по ст.8.2 КоАП РФ «Несоблюдение экологических и санитарно-эпидемиологических требований при обращении с отходами производства и потребления, веществами, разрушающими озоновый слой, или иными опасными веществами» (к примеру: Постановление Восьмого арбитражного апелляционного суда от 16 апреля 2014 г. N 08АП-1453/14; Постановление Восьмого арбитражного апелляционного суда от 31 августа 2012 г. N 08АП-6212/12; Постановление Федерального арбитражного суда Северо-Западного округа от 16 декабря 2013 г. N Ф07-9680/13 по делу N A44$1462 / 2013)^{3}$. Учитывая, что опасность отходов является квалифицирующим признаком данного состава, судьями в обоснование нарушений приводится Федеральный закон от 24 июня 1998 г. N 89-ФЗ «Об отходах производства и потребления», определяющий классификацию отходов по классам опасности и правовые основы обращения с отходами производства и потребления в целях предотвращения вредного воздействия отходов производства и потребления на здоровье человека и окружающую природную среду (Постановление Федерального арбитражного суда Поволжского округа от 23 октября 2008 г. N A57-2255/08-132) 4 .

Между тем, медицинские отходы не могут быть отнесены в полной мере к отходам производ-

\footnotetext{
Информационно-правовое обеспечение «Гарант»: Постановления Восьмого арбитражного апелляционного суда от 16 апреля 2014 г. N 08AП-1453/14; от 31 августа 2012 г. N 08АП-6212/12; Постановление Федерального арбитражного суда Северо-Западного округа от 16 декабря 2013 г. N Ф079680/13 по делу N A44-1462/2013

4 Информационно-правовое обеспечение «Гарант»: Постановление Федерального арбитражного суда Поволжского округа от 23 октября 2008 г. N A57-2255/08-132
} 
ства, так как обращение с медицинскими отходами идет на принципиально другой основе.

Так, в Федеральном законе от 24 июня 1998 г. N 89-Ф3 «Об отходах производства и потребления» приводится классификация отходов по классам опасности в зависимости от степени негативного воздействия на окружающую среду I-V. При этом в ч.2 ст.2 указанного Федерального закона предусмотрено, что отношения в области обращения с отходами лечебнопрофилактических учреждений (ЛПУ) регулируются “соответствующим законодательством Российской Федерации". Таким образом, нормы данного Федерального закона не могут быть признаны общими по отношению к обращению с медицинскими отходами. Предполагается существование самостоятельного комплекса правовых норм, регулирующих обращение с медицинскими отходами, отличных от норм ФЗ “Об отходах производства и потребления". Подразумевается, что "соответствующим" комплексом правовых норм являются нормы: определяющие основы охраны окружающей среды, здоровья граждан, их права и обязанности в данной сфере, гарантии их реализации; закрепляющие полномочия и ответственность, права и обязанности медицинских организаций и медицинских работников; устанавливающие обязательные санитарно-эпидемиологические (специальные) требования к обращению с отходами, образующимися в организациях при осуществлении медицинской и/ или фармацевтической деятельности.

Учитывая наличие вышеназанной нормы статьи, Федеральный закон от 24 июня 1998 г. N 89-ФЗ “Об отходах производства и потребления" подтверждает и специфичность отходов ЛПУ, как объектов, имеющих нечто характерное для данного конкретного объекта, и показывает, что решение вопросов в области обращения отходов ЛПУ имеет свою специфику.

Учитывая изложенное и принимая во внимание прямую отсылку в Федеральном законе РФ от 24 июня 1998 г. N 89-Ф3 «Об отходах производства и потребления» на иное - «соответствующее» законодательство в регулировании отношений в области обращения с отходами ЛПУ, указанный Федеральный закон не регулирует отношения в области обращений отходов ЛПУ. Таким образом, он не может быть положен в обоснование нарушений в области обращения медицинских отходов.

Так, Федеральным Арбитражным судом Западно-Сибирского округа в Постановлении от 18.12.2012 г. по делу А46-11542/20125 оставлено в

\footnotetext{
"Справочно-правовая система "Консультант Плюс": Постановление от 18.12.2012 г. по делу № А46-11542/2012
}

силе решение нижестоящей инстанции, признающее правомерным Предписание Роспотребнадзора, выданное организации, осуществляющей обращение с медицинскими отходами об устранении нарушений СанПин 2.1.7.2790-10, при этом суды обоснованно сослались на неприменение к рассматриваемым правоотношениям по обращению с медицинскими отходами положений об обращении отходов, содержащихся в $\Phi 3$ «Об отходах производства и потребления».

Рассмотрим, как же раскрывает понятие "отходы лечебно-профилактических учреждений" законодательство Российской Федерации.

Федеральный закон, определяющий правовые основы государственной политики в области охраны окружающей среды, №7-ФЗ "Об охране окружающей среды" от 20.12.2001г. понятие отходов не объясняет.

Закон, определяющий основы охраны здоровья граждан, а также закрепляющий права и обязанности медцинских учреждений и работников, - Федеральный закон от 21.11.2011г. №323-ФЗ "Об основах охраны здоровья граждан в Российской Федерации" в части 1 статьи 49 также, не раскрывая понятие "отходы лечебно-профилактических учреждений", приводит лишь понятие "медицинские отходы": "все виды отходов, в том числе и анатомические, патолого-анатомические, биохимические, микробиологические и физиологические, образующиеся в процессе осуществления медицинской деятельности и фармацевтической деятельности, деятельности по производству лекарственных средств и медицинских изделий".

Понятие "отходы лечебно-профилактических учреждений" ранее было закреплено в СанПиН 2.1.7.728-99. Санитарные правила и нормы СанПиН 2.1.7.728-99 "Правила сбора, хранения и удаления отходов лечебно-профилактических учреждений" (утв. постановлением Главного государственного санитарного врача РФ от 22 января 1999 г. N 2) 2.1.7. "Почва, очистка населенных мест, бытовые и промышленные отходы. Санитарная охрана почвы." Под отходами лечебно-профилактических учреждений понимались все виды отходов, образующихся в: "больницах, (общегородских, клинических, специализированных, ведомственных, в составе научно-исследовательского, учебного институтов), поликлиниках (в т.ч. взрослых, детских, стоматологических), диспансерах; станциях скорой медицинской помощи; станциях переливания крови; учреждениях длительного ухода за больными; научно-исследовательских институтах и учебных 
заведениях медицинского профиля; ветеринарных лечебницах; аптеках; фармацевтических производствах; оздоровительных учреждениях (санаториях, профилакториях, домах отдыха, пансионатах); санитарно-профилактических учреждениях; учреждениях судебно-медицинской экспертизы; медицинских лабораториях (в т.ч. анатомических, патологоанатомических, биохимических, микробиологических, физиологических); частных предприятиях по оказанию медицинской помощи".

Постановлением Главного государственного санитарного врача РФ от 04 Марта 2011 г. N 18 СанПин 2.1.7.728 - 99 "Правила сбора, хранения и удаления отходов лечебно - профилактических учреждений" отменен. Поэтому понятие отходов лечебно-профилактических учреждений, как того требует Федеральный закон от 24 июня 1998 г. N 89-ФЗ "Об отходах производства и потребления" в настоящее время не определено на законодательном уровне.

Без определения соответствующего понятийного аппарата несколько затруднительно применение "соответствующего законодательства" (отличного от Федерального закона от 24 июня 1998 г. N 89-ФЗ "Об отходах производства и потребления"), которым следует руководствоваться в вопросах обращения отходов лечебно-профилактических учреждений.

Для исключения подобных "затруднений" в применении законодательства в области обращения данного вида отходов, представляется возможным и, даже необходимым, проводить аналогию и уравнивание между понятиями "отходы лечебнопрофилактических учреждений" и "медицинские отходы", понимая под "отходами лечебно-профилактических учреждений" в том числе и "медицинские отходы", несмотря на различный 13-значный код, определяющий вид отходов, установленный в Приказе Министерства природных ресурсов РФ от 02.12.2002г. №786 ${ }^{6}$ (в частности, отходы ЛПУ относятся к коду 97000000000 0, а медицинские отходы - к коду 971000000000 0).

Специфичность в области обращений медицинских отходов а также в вопросах привлечения ЛПУ к ответственности подтверждается тем, что как было выше указано, Федеральный закон РФ «Об отходах производства и потребления» классифицирует отходы на 5 классов опасности в зависимости от степени негативного воздействия на окружающую среду (ст.4.1: I класс - чрезвычайно

6 «Российская газета», №12, 23.01.2003 опасные отходы; II класс - высокоопасные отходы; III класс - умеренно опасные отходы; IV класс - малоопасные отходы; V класс - практически неопасные отходы). А в отношении медицинских отходов федеральным классификационным каталогом отходов, утвержденным приказом Министерства природных ресурсов Российской Федерации от 02.12.2002 N 786, класс опасности по указанным категориям, не установлен. (Приказом Минприроды России от 30 сентября 2011 г. N 792 установлено, что вышеназванный приказ №786 признан утратившим силу. Однако Приказ Минприроды России №792 официально опубликован не был, в силу не ступил. Поэтому делаем вывод, что федеральный классификационный каталог отходов в настоящее время все еще действует).

Частью 3 ст.49 Федерального закона от 21.11.2011г. №323-Ф3 «Об основах охраны здоровья граждан в Российской Федерации» предусмотрено, что «классификация, правила сбора, использования, обезвреживания, размещения, хранения, транспортировки, учета и утилизации медицинских отходов устанавливаются уполномоченным федеральным органом исполнительной власти».

Данным Федеральным законом, а также требованиями санитарно-эпидемиологических правил и нормативов (СанПиН) 2.1.7.2790-10 «Санитарноэпидемиологические требования к обращению с медицинскими отходами», утвержденным постановлением Главного государственного санитарного врача Российской Федерации от 09.12.2010 N 163, в соответствии с Федеральным законом от 30.03.1999 N 52-Ф3 «О санитарно-эпидемиологическом благополучии населения» (пункт 2.1), определена классификация медицинских отходов по степени их эпидемиологической, токсикологической, радиационной опасности, а также негативного воздействия на среду обитания - по классам опасности (А-Д):

- $\quad$ класс A - эпидемиологически безопасные отходы, приближенные по составу к твердым бытовым отходам;

- $\quad$ класс Б - эпидемиологически опасные отходы;

- класс В - чрезвычайно эпидемиологически опасные отходы;

- $\quad$ класс Г - токсикологически опасные отходы 1 - 4 классов опасности;

- $\quad$ класс Д - радиоактивные отходы.

Указанная классификация дана на основании морфологического состава и загрязнения отходов патогенной микрофлорой, токсичными и радиоактивными веществами. Иной классификации для 
медицинских отходов, чем предусмотрено последними документами -по классам А, Б, В, Г, Д - не существует на законодательном уровне. Здесь следует отметить, что в 1979 г.Всемирная организация здравоохранения причислила медицинские отходы к группе опасных. Однако подобная классификация медицинских отходов в качестве «опасных» также не соответствует классификации, приведенной в Федеральном законе №89-ФЗ. До сих пор остаются нерешенными вопросы: к какой из группе опасности следует относить медицинские отходы - к высокоопасным, чрезвычайно опасным, умеренно-опасным, малоопасным, либо практически неопасным; а также - следует ли к опасным отходам причислять практически неопасные отходы ЛПУ такие как, например, отходы, образующиеся при использовании канцелярских принадлежностей.

Как мы видим, медицинские отходы имеют иную классификацию, отличную от классификации отходов, установленную в Федеральном законе «Об отходах производства и потребления». А законодательством не предусматривается, следует ли относить медицинские отходы к какому-либо классу опасности (I-V), определенному Федеральным законом от 24 июня 1998 г. N 89-ФЗ. Учитывая изложенное, при привлечении ЛПУ к административной ответственности за нарушения в области обращений с медицинскими отходами, проведение аналогии между классами опасности, принятыми для классифкации отходов в Федеральном законе “Об отходах производства и потребления" и классами, указанными в Федеральном законе “Об основах охраны здоровья граждан в Российской Федерации" и СанПиН 2.1.7.2790-10, представляется невозможным. Это еще раз подтверждает, что в настоящее время затруднительно привлечение к административной ответственности ЛПУ за несоблюдение требований Федерального закона №89ФЗ в отношениях с медицинскими отходами.

Требования по обращению с медицинскими отходами регулируются санитарно-эпидемиологическими требованиями (СанПиН 2.1.7.2790-10). Вменять нарушения в области обращения с отходами лечебно-профилактических учреждений, полномочен орган, на которого возложен контроль за соблюдением санитарно-эпидемиологнических требований. Такой службой является Роспотребнадзор. На этом основании представления, вынесенные иными органами, на которых возложены иные функции, связанные с охраной окружающей среды, атмосферного воздуха, обращения отходов производства и потребления (например, Департа- мент природно-ресурсного регулирования) могут быть оспорены лечебно-профилактическими учреждениями и признаны недействительными.

Особо остро стоит вопрос лицензирования деятельности по обращению медицинских отходов. Согласно пункту 30 статьи 12 Федерального закона от 4 мая 2011 г. N 99-Ф3 «0 лицензировании отдельных видов деятельности», установлено, что подлежит лицензированию деятельность по обезвреживанию и размещению отходов I - IV классов опасности. Статьяgarantf1://12015118.22/ 22 Федерального закона от 30.03.1999 N 52-Ф3 «О санитарно-эпидемиологическом благополучии населения» предусматривает, что «отходы производства и потребления подлежат сбору, использованию, обезвреживанию, транспортировке, хранению и захоронению... в соответствии с санитарными правилами и иными нормативными правовыми актами Российской Федерации».

С 01.07.2009 с принятием Федерального закона от 30.12.2008 N 309-Ф3 «0 внесении изменений в статью 16 Федерального закона «Об охране окружающей среды» и отдельные законодательные акты Российской Федерации», отношения в области обращения с отходами лечебно-профилактических учреждений исключены из сферы действия Федерального закона от 24.06.1998 N 89-Ф3 «Об отходах производства и потребления «, которыми установлены соответствующие классы опасности, деятельность по обезвреживанию и размещению которых подлежит лицензированию.

Действующая редакция Федерального закона от 4 мая 2011 г. N 99-Ф3 «О лицензировании отдельных видов деятельности», требующая лицензирование лишь деятельности по обезвреживанию и размещению отходов I - IV классов опасности, опять же не предусмаривает необходимость лицензирования деятельности в области обращений медицинских отходов классов А-Д.

Требования к организации системы обращения с медицинскими отходами, требования к их сбору, временному хранению, транспортированию, способы и методы обеззараживания и/или обезвреживания медицинских отходов, правила учета и контроля за движением медицинских отходов, требования к организации участка по обращению с медицинскими отходами установлены лишь отдельными разделами СанПиН 2.1.7.2790-10, которые также не регулируют вопросы лицензирования деятельности в области обращений с медицинскими отходами.

Из изложенного и из анализа ч.2 ст.2 Федерального закона N 89-ФЗ «Об отходах производ- 
ства и потребления «, п.30 ст.12 Федерального закона N 99-Ф3 «О лицензировании отдельных видов деятельности», который прямо корреспондирует к ст.4.1. Закона №89-Ф3, следует вывод, что в настоящее время законодательно не предусмотрена обязанность по лицензированию деятельности по обращению с медицинскими отходами не только ЛПУ, но и иных организаций, которые на основании заключаемых с медицинскими организациями договоров осуществляют транспортировку, обеззараживание и размещение отходов. Безусловно, что отсутствие соответствующего законодательства в области лицензирования деятельности по обращению с медицинскими отходами служит особым фактором риска: увеличения количества недобросовестных лиц, нарушающих экологические и санитарно-эпидемиологические требований при обращении с отходами, злоупотребления ими наличием недостаточности правовых норм, регулирующих вопросы лицензирования в области обращения медицинских отходов; возможного возникновения и распространения инфекционных и иных заболеваний. Поэтому данный вопрос особо актуален и требует срочного решения на федеральном уровне путем принятия соответствующих законов.

Особой проблемой при привлечении ЛПУ и организаций, занимающихся сбором, транспортировкой и размещением медицинских отходов является существование в настоящее время различных вариантов толкования содержания понятия «обращение с медицинскими отходами».

Ч. 3 ст. 49 Ф3 «Об основах охраны здоровья граждан в РФ», под обращением с медицинскими отходами понимает следующие действия: сбор, использование, обезвреживание, размещение, хранение, транспортировка, учет и утилизация медицинских отходов.

В п. 1.2. Санитарно-эпидемиологических правил и нормативов СанПиН 2.1.7.2790-10, утвержденных Постановлением Главного государственного санитарного врача РФ от 09.12.2010 № 163 (далее - СанПиН 2.1.7.2790-10), в понятие «обращение» включены: сбор, временное хранение, обеззараживание, обезвреживание, транспортирование.

Согласно положениям Номенклатуры работ и услуг в здравоохранении (утв. Минздравсоцразвития РФ 12.07.2004) ${ }^{7}$, выделяют три элемента обра-

М., Номенклатура работ и услуг в здравоохранении (утв. Минздравсоцразвития РФ 12.07.2004) // М., Издательство «Ньюдиамед», 2004 щения с медицинскими отходами: сбор, сортировка, транспортировка.

Естественно, что такая «недоработка» в законодательстве представляет возможность наиболее вольной трактовки понятия «обращения медицинских отходов» и ухода от ответственности виновных организаций, участвующих в обращении медицинских отходов.

В настоящее время существует отсутствие единого понимания и по вопросам паспортизации медицинских отходов.

Согласно ст. 14 ФЗ «Об отходах производства и потребления», на отходы 1-4 класса опасности должен быть составлен паспорт. А поскольку обращение с медицинскими отходами регулируется иным законодательством, а «иным законодательством» в свою очередь вопросы паспортизации медицинских отходов не урегулированы, следовательно фактически в настоящее время законодательно не закреплена необходимость паспортизации медицинских отходов.

В то же время распространена судебная практика, когда отсутствие паспортов медицинских отходов служит основанием для привлечения ЛПУ к административной ответственности (напр. Постановление Пятнадцатого Арбитражного Апелляционного суда № 15АП0122997/2012 от 13.12.1012 г. по делу № A32-49225/20118).

Отсутствие: самого понятия «медицинские отходы»; соответствующего четкого законодательного закрепления вопросов в области лицензирования деятельности в области обращения с медицинскими отходами и паспортизации медицинских отходов; несоответствие классификации медицинских отходов классам опасности, указанным в Федеральном законе «Об отходах производства и потребления» служит причиной недостаточного регулирования и контроля данного вида деятельности и как следствие - неправильного обращения с медицинскими отходами. Что в свою очередь не только повышает возможность непривлечения к ответственности недобросовестных в вопросах обращения с медицинскими отходами учреждений, но и увеличивает риски нанесения ущерба окружающей среде и заражения и травм населения в целом, и работников здравоохранения в частности.

\footnotetext{
8 “Справочно-правовая система "Консультант Плюс": Постановление № 15АП0122997/2012 от 13.12.1012 г. по делу № A32-49225/2011
} 
Библиография:

1. Федеральный закон от 21 ноября 2011 г. N 323-Ф3 Об основах охраны здоровья граждан в Российской Федерации // Российская газета N 263, 23.11.2011 г.

2. Федеральный закон от 24 июня 1998 г. N 89-Ф3 "Об отходах производства и потребления"// Собрание законодательства Российской Федерации от 29 июня 1998 г. N 26 ст. 3009

3. Федеральный закон от 30.12.2008 N 309-ФЗ О внесении изменений в статью 16 Федерального закона "Об охране окружающей среды" и отдельные законодательные акты Российской Федерации // Российская газета, N 267, 31.12.2008

4. Федеральный закон от 30 марта 1999 г. N 52-Ф3 "О санитарно-эпидемиологическом благополучии населения"// Собрание законодательства Российской Федерации от 5 апреля 1999 г. N 14 ст. 1650

5. Приказ Министерства природных ресурсов РФ от 2 декабря 2002 г. N 786"Об утверждении федерального классификационного каталога отходов" // Российская газета, №12, 23.01.2003

6. Номенклатура работ и услуг в здравоохранении (утв. Минздравсоцразвития РФ 12.07.2004) // М., Издательство "Ньюдиамед", 2004

7. СанПиН 2.1.7.2790-10 "Санитарно-эпидемиологические требования к обращению с медицинскими отходами", утвержденным постановлением Главного государственного санитарного врача Российской Федерации от 09.12.2010 N 163// Информационно-правовое обеспечение «Гарант». Судебная практика

8. Постановление Восьмого арбитражного апелляционного суда от 16 апреля 2014 г. N 08AП-1453/14 // Информационно-правовое обеспечение «Гарант»

9. Постановление Восьмого арбитражного апелляционного суда от 31 августа 2012 г. N 08АП-6212/12 // Информационно-правовое обеспечение «Гарант»

10. Постановление Федерального арбитражного суда Северо-Западного округа от 16 декабря 2013 г. N Ф07-9680/13 по делу N A44-1462/2013 // Информационно-правовое обеспечение «Гарант»

11. Постановление Федерального арбитражного суда Поволжского округа от 23 октября 2008 г. N A57-2255/08-132 // Информационно-правовое обеспечение «Гарант»

12. Постановление № 15АП0122997/2012 от 13.12.1012 г. по делу № А32-49225/2011// Справочно-правовая система "Консультант Плюс":

13. Постановление от 18.12.2012 г. по делу № А46-11542/2012 // Справочно-правовая система "Консультант Плюс"

14. Акимкин В.Г. Санитарно-эпидемиологические требования к организации сбора, обезвреживания, временного хранения и удаления отходов в лечебно-профилактических учреждениях: Методическое пособие.-М.: Издательство РАМН, 2004.-84 c.

15. Акимикин В. Г. Организационно-эпидемиологические аспекты обращения с отходами лечебно-профилактических учреждений// Эпидемиология и инфекционные болезни. 2005.-№2.

16. Опарин П.С. Бактериологическая экспертиза больничных отходов // Эпидемиология и инфекционные болезни.-2002.-№5. - С.35-37

17. Степанов Е.В. Административно-правовое регулирование порядка ор-ганизации и проведения конкурсов на услуги по утилизации медицинских отходов // Право и жизнь. 2009. №3. С. 144-162. 1,26 п.л.

18. Щипанов М.М. Утилизация отходов лечебно-профилактических учреждений как часть государственной политики в сфере здравоохранения Российской Федерации // Современное право. 2008. N 1 (1). С. $21,22$.

19. Степаненко В.С. Экологическая политика в области обращения с отходами в ЕС и в России // NB: Национальная безопасность. - 2012. - 2. - С. 48 - 102. URL: http://www.e-notabene.ru/nb/article_297.html

20. Нобель А.Р. Вопросы использования в доказывании по делам об административных правонарушениях в области охраны окружающей среды иных протоколов, предусмотренных КоАП РФ, и документов, полученных в результате осуществления государственного контроля (надзора) и муниципального контроля // Административное и муниципальное право. - 2013. - 7. - С. 767 - 769. DOI: 10.7256/1999-2807.2013.7.9057.

21. Костенников М.В. К вопросу о некоторых актуальных проблемах административного права // NB: Административное право и практика администрирования. - 2013. - 4. - C. 71 - 95. DOI: 10.7256/2306-9945.2013.4.8840. URL: http://www.e-notabene.ru/al/article_8840.html

\section{References (transliterated):}

1. Federal'nyi zakon ot 21 noyabrya 2011 g. N 323-FZ Ob osnovakh okhrany zdorov'ya grazhdan v Rossiiskoi Federatsii // Rossiiskaya gazeta N 263, 23.11.2011 g.

2. Federal'nyi zakon ot 24 iyunya 1998 g. N 89-FZ "Ob otkhodakh proizvodstva i potrebleniya" // Sobranie zakonodatel'stva Rossiiskoi Federatsii ot 29 iyunya 1998 g. N 26 st. 3009

3. Federal'nyi zakon ot 30.12.2008 N 309-FZ O vnesenii izmenenii v stat'yu 16 Federal'nogo zakona "Ob okhrane okruzhayushchei sredy" i otdel'nye zakonodatel'nye akty Rossiiskoi Federatsii // Rossiiskaya gazeta, N 267, 31.12 .2008

4. Federal'nyi zakon ot 30 marta 1999 g. N 52-FZ "O sanitarno-epidemiologicheskom blagopoluchii naseleniya"// Sobranie zakonodatel'stva Rossiiskoi Federatsii ot 5 aprelya 1999 g. N 14 st. 1650 
Административное и муниципальное право $10(82) \cdot 2014$

5. Prikaz Ministerstva prirodnykh resursov RF ot 2 dekabrya 2002 g. N 786"Ob utverzhdenii federal'nogo klassifikatsionnogo kataloga otkhodov" // Rossiiskaya gazeta, №12, 23.01.2003

6. Nomenklatura rabot i uslug v zdravookhranenii (utv. Minzdravsotsrazvitiya RF 12.07.2004) // M., Izdatel'stvo "N'yudiamed", 2004

7. SanPiN 2.1.7.2790-10 "Sanitarno-epidemiologicheskie trebovaniya k obrashcheniyu s meditsinskimi otkhodami", utverzhdennym postanovleniem Glavnogo gosudarstvennogo sanitarnogo vracha Rossiiskoi Federatsii ot 09.12 .2010 N 163// Informatsionno-pravovoe obespechenie «Garant». Sudebnaya praktika

8. Postanovlenie Vos'mogo arbitrazhnogo apellyatsionnogo suda ot 16 aprelya 2014 g. N 08AP-1453/14 // Informatsionnopravovoe obespechenie «Garant»

9. Postanovlenie Vos'mogo arbitrazhnogo apellyatsionnogo suda ot 31 avgusta 2012 g. N 08AP-6212/12 // Informatsionnopravovoe obespechenie «Garant»

10. Postanovlenie Federal'nogo arbitrazhnogo suda Severo-Zapadnogo okruga ot 16 dekabrya 2013 g. N F07-9680/13 po delu N A44-1462/2013 // Informatsionno-pravovoe obespechenie «Garant»

11. Postanovlenie Federal'nogo arbitrazhnogo suda Povolzhskogo okruga ot 23 oktyabrya 2008 g. N A57-2255/08-132 // Informatsionno-pravovoe obespechenie «Garant»

12. Postanovlenie № 15AP0122997/2012 ot 13.12.1012 g. po delu № A32-49225/2011// Spravochno-pravovaya sistema "Konsul'tant Plyus":

13. Postanovlenie ot 18.12.2012 g. po delu № A46-11542/2012 // Spravochno-pravovaya sistema "Konsul'tant Plyus"

14. Akimkin V.G. Sanitarno-epidemiologicheskie trebovaniya k organizatsii sbora, obezvrezhivaniya, vremennogo khraneniya i udaleniya otkhodov v lechebno-profilakticheskikh uchrezhdeniyakh: Metodicheskoe posobie.-M.: Izdatel'stvo RAMN, 2004.-84 s.

15. Akimikin V. G. Organizatsionno-epidemiologicheskie aspekty obrashcheniya s otkhodami lechebno-profilakticheskikh uchrezhdenii// Epidemiologiya i infektsionnye bolezni. 2005.-№2.

16. Oparin P.S. Bakteriologicheskaya ekspertiza bol'nichnykh otkhodov // Epidemiologiya i infektsionnye bolezni.-2002.-№5. - S.35-37

17. Stepanov E.V. Administrativno-pravovoe regulirovanie poryadka or-ganizatsii i provedeniya konkursov na uslugi po utilizatsii meditsinskikh otkhodov // Pravo i zhizn'. 2009. №3. S. 144-162.1,26 p.l.

18. Shchipanov M.M. Utilizatsiya otkhodov lechebno-profilakticheskikh uchrezhdenii kak chast' gosudarstvennoi politiki v sfere zdravookhraneniya Rossiiskoi Federatsii // Sovremennoe pravo. 2008. N 1 (1). S. 21, 22.

19. Stepanenko V.S. Ekologicheskaya politika v oblasti obrashcheniya s otkhodami v ES i v Rossii // NB: Natsional'naya bezopasnost'. - 2012. - 2. - C. 48 - 102. URL: http://www.e-notabene.ru/nb/article_297.html

20. Nobel' A.R. Voprosy ispol'zovaniya $\mathrm{v}$ dokazyvanii po delam ob administrativnykh pravonarusheniyakh $\mathrm{v}$ oblasti okhrany okruzhayushchei sredy inykh protokolov, predusmotrennykh KoAP RF, i dokumentov, poluchennykh $\mathrm{v}$ rezul'tate osushchestvleniya gosudarstvennogo kontrolya (nadzora) i munitsipal'nogo kontrolya // Administrativnoe i munitsipal'noe pravo. - 2013. - 7. - C. 767 - 769. DOI: 10.7256/1999-2807.2013.7.9057.

21. Kostennikov M.V. K voprosu o nekotorykh aktual'nykh problemakh administrativnogo prava // NB: Administrativnoe pravo i praktika administrirovaniya. - 2013. - 4. - C. 71 - 95. DOI: 10.7256/2306-9945.2013.4.8840. URL: http://www.enotabene.ru/al/article_8840.html 